Published in: Acta mater. Vol. 47, 1999, pp. 3855-3868

\title{
MICROSTRUCURE AND STRENGTHENING OF Al-Li-Cu-Mg ALLOYS AND MMCs: $\quad$ II. MODELLING OF YIELD STRENGTH
}

\author{
M.J. Starink, P. Wang, I. Sinclair and P.J. Gregson \\ Materials Group, School of Engineering Sciences, \\ University of Southampton, Southampton S017 1BJ, UK
}

Keywords: precipitation, strengthening, Al-Li-Cu-Mg, MMC, PFZ

\begin{abstract}
A detailed quantitative model for the strengthening of monolithic alloys and composites due to precipitation strengthening, solution strengthening, grain and subgrain strengthening, strengthening by dislocations and load transfer to ceramic inclusions is presented. The model includes a newly derived description of the effect of a precipitate free zone (PFZ) around the reinforcing phase incorporating strain hardening of the PFZ. The model is successfully applied to model the experimental data for the proof strengths of four $\mathrm{Al}-\mathrm{Li}-\mathrm{Cu}-\mathrm{Mg}$ type alloys and composites aged to obtain a wide range of microstructures and all strengthening contributions are quantified. It is shown that PFZ formation in the 8090 MMC causes a drastic reduction in the proof strength (about $100 \mathrm{MPa}$ ), but it has little influence on the time required for peak ageing. In all alloys strengthening due to GPB zones is more important than strengthening due to $\delta^{\prime}\left(\mathrm{Al}_{3} \mathrm{Li}\right)$ phase.
\end{abstract}

\section{Introduction}

The modelling of strength in precipitation hardened alloys goes back to 1940s with ground braking work by Mott and Nabarro [1] and Orowan [2]. More recent substantial contributions in this field are for instance those by Ardell [3] and Nembach and Neite [4]. In materials with added ceramic reinforcement, load transfer between matrix and reinforcement additionally strengthens the resulting composite. For the modelling of this type of strengthening Eshelby's work $[5,6]$ in the 1950s has proved to be an important starting point. Similarly, other strengthening mechanisms, like grain strengthening, dislocation strengthening and solid solution strengthening, have been the subject of earlier work (see e.g. Refs. [7,8,9,10,11,12,13,14] and references therein). Hence, a considerable body of work on modelling of strength in alloys and composites exists and one of the main challenges for materials scientists today is the merging of the models for the different strengthening contributions to arrive at a detailed description of the strengthening in complex alloys and composites on the basis of microstructural observations. This type of complex strength modelling has been performed, to varying degree of detail, for several monolithic precipitation hardened alloys $[11,15,16,17,18]$, but a detailed model of strengthening in precipitation hardened metal matrix composites (MMCs) has not been reported to date. 
The goal of the present paper is threefold. Firstly, we want to construct a detailed and generally applicable model for strengthening in heat treatable MMCs. As indicated above, many components of such a model have been presented before in the literature but, as will be shown, a new model of the interaction between precipitation and ceramic reinforcement is necessary to obtain a detailed constitutive model for MMCs. The second goal is the merging of the strengthening model with kinetic models for the evolution of microstructure during ageing of precipitation hardened alloys. The third aim is to compare the model predictions with measured proof strengths of MMCs based on a complex precipitation hardened alloy system. For the latter the 8090 (Al-Li-Cu-Mg-Zr) Albased alloy system is chosen. This alloy system is especially suited for a thorough investigation of the generally applicable model for strengthening in heat treatable MMCs (presented in section 3) as it contains most, if not all, of the complex microstructural elements that influence strengthening in complex commercial alloys and their MMCs. For instance, precipitation strengthening in 8090 MMCs contains contributions from modulus hardening, order hardening and dispersion hardening mechanisms, whilst load transfer is influenced by the formation of a precipitate free zone (PFZ) around the reinforcing particles. In the companion paper [19] the development of the microstructures of 4 reinforced and unreinforced Al-Li-Cu-Mg-Zr alloys during ageing was analysed and modelled. In the present paper these results are used to model and predict the strength of the reinforced and unreinforced $\mathrm{Al}-\mathrm{Li}-\mathrm{Cu}-\mathrm{Mg}-\mathrm{Zr}$ alloys at various stages of the ageing process.

In the strength modelling approach adopted in the present paper, the strengthening of MMCs and monolithic alloys are ascribed to five mechanisms:

1) Precipitation strengthening.

This involves strengthening of grains due to precipitates. In the case of the present $\mathrm{Al}-\mathrm{Cu}-\mathrm{Mg}-\mathrm{Li}$ alloys the strengthening precipitates are GPB zones, $\delta^{\prime}\left(\mathrm{Al}_{3} \mathrm{Li}\right)$ phase and $\mathrm{S}^{\prime}\left(\mathrm{Al}_{2} \mathrm{CuMg}\right)$ phase [20,21], with a small contribution due to $\beta^{\prime}\left(\mathrm{Al}_{3} \mathrm{Zr}\right)$ dispersoids [12].

2) Solution strengthening.

This involves strengthening of a phase due to dissolved atoms. In the case of our Al-Cu-Mg- $\mathrm{Li}$ alloys this involves strengthening of the Al-rich phase by dissolved $\mathrm{Li}, \mathrm{Cu}$ and $\mathrm{Mg}$ atoms.

3) Grain and subgrain strengthening.

This involves the strengthening due to hampering of dislocation movement by the presence of (sub-) grain boundaries.

4) Dislocation density.

This involves the strengthening of the Al-rich phase grains due to impeding of dislocation movement by the presence of dislocations, which have formed as a result of prior plastic deformation. In MMCs the main cause for prior plastic deformation is the misfit of ceramic inclusions after heat treatment, which results from the difference in thermal expansion of matrix and ceramic inclusion.

5) Load transfer between matrix and reinforcement in MMCs.

Load transfer between matrix and reinforcement results from the different stiffness of these two main phases. In MMCs the ceramic reinforcement is generally stiffer than the matrix and thus, on deformation, stresses in the ceramic reinforcement will be larger as those in the matrix.

For most of these strengthening mechanisms a range of theoretical expressions are available in the literature. For the present paper an extended assessment of the literature has been performed and the 
expressions that appear to have been most successful will be presented in section 3 . They will be used in assessing the strengthening of the present MMCs and monolithic alloy. For some strengthening mechanisms no expressions are available from the literature and these cases new models have been derived to deal with these strengthening mechanisms. The latter is the case for the strengthening due to load transfer in the presence of precipitate free zones (PFZs) around the reinforcement (section 3.7). The comparison between experimental data on yield strength of the four alloys and the model predictions is presented in section 4 .

\section{Experimental}

The alloys were produced as hot rolled sheet via a powder metallurgical route (see Refs. [22,23]). Details on production route, compositions and heat treatments are given in the companion paper [19]. The grain sizes and PFZs were studied by TEM [19].

\section{$3 \quad$ Modelling of strengthening in alloys and MMCs}

\subsection{Strengthening of grains by precipitation.}

Crystals under a shear stress deform by the movement of dislocations. The presence of precipitates in a crystal can strengthen a crystal by impeding the movement of dislocations. The strengthening effect depends on the force needed to shear the obstacles (precipitates), and their density. In this paper we will use well known expressions of strengthening in crystals as presented for instance in Refs. $[3,15,24]$. Several strengthening mechanisms need to be considered [3]:

a) Dispersion strengthening

b) Order strengthening

c) Stacking fault strengthening

d) Modulus hardening

In the following we will consider the mechanisms by which the precipitates in our alloys contribute to the strengthening of the grains and present the equations which quantify these contributions.

\subsection{1 $\delta^{\prime}$ phase strengthening}

Although, in principle, $\delta^{\prime}$ phase can strengthen the $\mathrm{Al}$ grains via various precipitate strengthening mechanisms, it has been established that in all practical cases order hardening is the dominant factor $[12,15]$. The strengthening due to an ordered phase like $\delta^{\prime}$ phase depends on the way the dislocations interact with the precipitate, and several slightly different expressions for this type of strengthening have been proposed in the literature $[3,15,18,25,26,27,28]$. In the underaged state the generalised form for these expressions is:

$$
\Delta \tau_{\text {огd } \text { иа }}=\frac{\gamma_{\text {apb }}}{2 b}\left(\sqrt{\frac{3 \pi^{2} \gamma_{a p b} f \bar{r}}{32 \Gamma}}+B f\right)
$$


where $\gamma_{a p b}$ is the anti phase boundary energy on $\{111\}$ planes, $f$ is the volume fraction of precipitates, $\bar{r}$ is the average radius of the precipitates, $B$ is a constant which depends on the type interaction between dislocations and precipitate and $\Gamma$ is the line tension, which can be calculated using the expressions presented in Refs. [3,15] (using the so-called Friedel spacing [3,15]). In publications on strengthening due to $\delta^{\prime}$ phase $B$ has been argued to equal either -1 [15,16], 0 [27,28] or 2.5 [26]. In published comparisons of the resulting expressions with experimental data, $\gamma_{a p b}$ is treated as a fittable parameter and thus the value of $\gamma_{a p b}$ will depend on the choice for $B$. For our present purpose it is important to note that several combinations of $B$ and $\gamma_{a p b}$ can yield similarly good descriptions of the CRSS of $\delta^{\prime}$ phase strengthened Al-Li alloys, and thus the value chosen for $B$ will not have a significant influence on the accuracy of the present model. We will base our analysis on the expressions presented in Refs. [27,28], which yield good fits to measured CRSS of Al-Li single crystals and which appear to be consistent with the physics of the interaction between dislocation and precipitate [27,28]. Adopting the value of $\gamma_{a p b}$ for binary Al-Li from Ref. [27] can introduce some level of error into the model as for the 8090 alloys as minor amounts of $\mathrm{Mg}$ may be incorporated in the $\delta$ ' phase [29] and alter $\gamma_{a p b}$. We will estimate that this introduces an uncertainty of about $10 \%$ in the value for $\gamma_{a p b}$. (The addition of $0.4 \mathrm{wt} \% \mathrm{Ag}$ to Al-Li appears to increase $\gamma_{a p b}$ by about $8 \%$ [28].)

For precipitates in an underaged state the appropriate expression for order hardening is:

$$
\Delta \tau_{\text {ord иа }}=\frac{\gamma_{a p b}}{2 b}\left(\sqrt{\frac{3 \pi^{2} \gamma_{a p b} f \bar{r}}{32 \Gamma}}\right)
$$

When precipitates are relatively large and strong and the alloy is near its peak aged condition the above "weak obstacle" treatment is no longer valid and the appropriate "strong particle" expression for order hardening is [28]:

$$
\Delta \tau_{\text {ord }, p a}=0.81 \frac{\gamma_{a p b}}{2 b}\left(\sqrt{\frac{3 \pi f}{8}}\right)
$$

For our 8090 alloy the change-over $\left(\Delta \tau_{\text {ord,ua }}=\Delta \tau_{\text {ord,pa }}\right)$ is at about $r_{\delta^{\prime}}=21 \mathrm{~nm}$.

The change-over from the weak particle to the strong particle regime is relatively abrupt [28] and hence the total strengthening due to order hardening can be obtained to a sufficient accuracy by:

$$
\Delta \tau_{\text {ord }}=\operatorname{Min}\left\{\Delta \tau_{\text {ord }, u a}, \Delta \tau_{\text {ord }, p a}\right\}
$$

The $\delta^{\prime}$ sizes in our alloys are within the range of sizes for which Eq. 1 has been verified for binary Al-Li alloys [27,28]. 


\subsubsection{GPB zone strengthening}

GPB zones are generally considered not to be ordered and hence order hardening is not applicable. Instead GPB zones are thought to strengthen crystals mainly as a result of modulus strengthening (see also Ref. [12]). Modulus hardening is a difficult strengthening mechanism to deal with theoretically [3], leading to quite complex expressions. At present we will adopt the very much simplified treatment by Cartaud et al [30] (see also Ref. [12]) according to which the strengthening due to difference in shear modulus is approximated by:

$$
\Delta \tau_{\bmod }=\frac{\Delta G}{4 \pi \sqrt{2}} \sqrt{f}
$$

where $\Delta G$ is the difference in shear modulus between zones and surrounding metallic phase. The shear modulus of GPB zones, $G_{G P B}$, is estimated to equal the average of the moduli of $\mathrm{Mg}, G_{M g}$, and that of $\mathrm{Cu}, G_{C u}$ (see also Ref. [12]):

$$
G_{G P B}=\frac{G_{M g}+G_{C u}}{2}
$$

The assumption (implied in Eq. 5) that strengthening due to the zones is independent of the size of the zones differs from other, more complex models (see e.g. Refs. [3,31]), but some theoretical justification may be found in the rather weak size dependency obtained in the modulus hardening model due to Nembach [31]. The accuracy of these simplified expressions for prediction of strengthening due to GPB zones will be further discussed in section 4.1, where they will be compared with experimental data for ternary $\mathrm{Al}-\mathrm{Cu}-\mathrm{Mg}$ alloys.

\subsubsection{S' phase strengthening}

S' precipitates are rod shaped particles with a very high length to diameter ratio $(>10)$ and a crosssection that is approximately circular [19]. They are aligned along $\mathrm{Al}<100>$ directions and, hence, dislocations which move mainly on $\{111\}$ planes will effectively experience the $\mathrm{S}^{\prime}$ precipitates as an obstacle which is nearly equiaxed. After $1 \mathrm{~h}$ or longer ageing at $170^{\circ} \mathrm{C}$ the diameter of $\mathrm{S}^{\prime}$ precipitates observed in the present alloys are generally larger than the critical diameter for shearing of S', which is about $2 \mathrm{~nm}$ [32], and thus they will be looped via the well-known Orowan looping mechanism. Smaller diameters of $S^{\prime}$ generally coincide with near to negligible $S^{\prime}$ volume fractions, and hence this mechanism is appropriate for describing the strengthening due to $S^{\prime}$ precipitates for our alloys in the heat treated conditions studied.

For equi-axed particles the strengthening is due to dispersion strengthening and the appropriate strengthening contribution is given by [33]: 


$$
\Delta \tau_{d i s}=0.81 \frac{G b}{2 \pi(1-v)^{1 / 2}}\left(\frac{\ln (d / b)}{0.615 d(2 \pi / 3 f)^{1 / 2}-d}\right)
$$

where $d$ is the diameter of the precipitates. We will assume that this equation is a valid approximation for $\mathrm{S}^{\prime}$ strengthening and take $\mathrm{d}$ as the diameter of the $\mathrm{S}$ ' rods.

\subsection{Strengthening of grains by dissolved atoms.}

For solution strengthening a number of different models have been proposed. Following the work by Gomiero et al. [12] we will here use a description that takes account of size effects, modulus effects and short range order (SRO) effects.

Strengthening due to the size effect of dissolved atoms is given by:

$$
\Delta \tau_{\text {sol, size }}=2^{1 / 3} G\left(0.1 \varepsilon_{\text {size }}\right)^{4 / 3} c^{2 / 3}
$$

where $c$ is the solute concentration, values for $\varepsilon_{\text {size }}$ are given in [12]. Strengthening by dissolved atoms due to the modulus effect is given by:

$$
\Delta \tau_{\text {sol, } \bmod }=2^{1 / 3} G\left[\frac{1}{32 \pi^{2}} \frac{\eta_{\bmod }}{1+\frac{1}{2} \eta_{\bmod }}\right] c^{2 / 3}
$$

values for $\eta_{\text {mod }}$ are given in [12]. Strengthening due to short range order of dissolved atoms is given by:

$$
\Delta \tau_{\text {sol,SRO }}=\frac{c(1-c)}{3 b^{3}} A_{S R O}
$$

where $A_{S R O}$ is a parameter depending on nearest neighbour interaction parameters and WarrenCowley parameters, details of the calculations of these parameters in presented in [12,34].

As $\mathrm{Cu}$ and $\mathrm{Mg}$ have exactly opposing size effects they will tend to cluster when both types of atoms are present in the Al-rich phase. Hence for calculation of the solution strengthening contributions the effective concentrations of $\mathrm{Cu}$ and $\mathrm{Mg}$ in the Al-rich phase equal 0 and $\left(\mathrm{x}_{\mathrm{Mg}}-\mathrm{x}_{\mathrm{Cu}}\right)$, respectively. The latter three equations indicate that for the present alloys only solution strengthening due to $\mathrm{Mg}$ is truly important ( $\Delta \tau_{\text {sol }} \sim 10 \mathrm{MPa}$, mainly due to the size effect) with solution strengthening due to $\mathrm{Li}$ $\left(\Delta \tau_{\text {sol }} \sim 3 \mathrm{MPa}\right)$ and $\mathrm{Cu}\left(\Delta \tau_{\text {sol }}<0.5 \mathrm{MPa}\right)$ being small to totally insignificant. 


\subsection{Superposition of the grain strengthening mechanisms.}

If two or more types of strengthening obstacles are present in a grain, the total CRSS of the grain will be a superposition of the strengthening of the individual types of strengthening obstacles. A general approximation for the strengthening in a grain due to $\mathrm{N}$ obstacles, 1,2,3 $\ldots \mathrm{N}$, is (see also Refs. [16,18,24]):

$$
\left(\Delta \tau_{\Sigma}\right)^{q}=\sum_{i=1}^{M}\left(\Delta \tau_{i}\right)^{q}
$$

Thus the superposition problem is reduced to finding the values for $q$ that are appropriate for the superposition of a different sets of obstacles. Below, we will discuss the available data for the $q$ values that are relevant to our alloys, starting the superposition of strengthening due to precipitates.

Fits to computer simulations [35] of particle-dislocation interactions in materials containing groups of obstacles with differing strengths have shown [24] that for strengthening due to two types of obstacles which have equal strengths, the above equation with $q=2$ gives a good description of the overall strengthening. However, when the obstacle strength of the precipitates is different but of the same order of magnitude, $q$ can vary between about 1.4 and 2, depending on the ratio of the strengths of the obstacles [16]. It has been shown [16] that for the superposition of $T_{1}$ and $\delta^{\prime}$ precipitate strengthening in underaged $\mathrm{Al}-\mathrm{Li}-\mathrm{Cu}$ type alloys $q=1.4$ generally yields the most consistent results. This value of $q$ is consistent with the mentioned computer modelling as in the underaged $\mathrm{Al}-\mathrm{Li}-\mathrm{Cu}$ the obstacle strength of $\mathrm{T}_{1}$ is consistently greater than the obstacle strength of $\delta^{\prime}[16]$. In the case of our Al-Li-Cu-Mg alloys the $\delta^{\prime}, \beta^{\prime}$ and $S^{\prime}$ strengthening precipitates have similar strengths but the strength of the GPB zones is much lower. Hence, to obtain a realistic superposition of the strengthening due to these 4 precipitates/zones at least two different values for $q$ are necessary: $q$ for superposition of strengthening contributions due to precipitates $\left(\delta^{\prime}, \beta^{\prime}\right.$ and $\left.S^{\prime}\right)$, $q_{p p t}$, and $q$ for superposition of precipitate and zone strengthening, $q_{z o n e}$. The relative strengths of the 3 types of precipitate will vary with ageing time, which will cause $q_{p p t}$ to vary with ageing time. Taking account of these complicating factors will cause the model to become prohibitively convoluted and hence it is assumed that superposition of precipitate strengthening can be approximated using one single value of $q_{p p t}$. Following the work on the superposition of $\mathrm{T}_{1}$ and $\delta^{\prime}$ precipitate strengthening in Al-Li-Cu type alloys $[15,16] q_{p p t}=1.4$ will be used throughout. This simplifying assumption will cause some variation in the accuracy of the model. As a rough indication it is estimated that $q_{p p t}$ varies by $20 \%$ either side of the average value and this leads to variation in the predicted yield strength of up to $\pm 22 \mathrm{MPa}$ (about $5 \%$ of the total yield strength) for the monolithic 8090 alloy and the 8090 MMC close the peak aged condition.

The strength of GPB zones is very much lower than the strength of the precipitates and hence $q_{\text {zone }}$ should be lower than $q_{p p t}$. It is thought that $q_{\text {zone }}$ is approximately equal to the value of $q$ for superposition of dissolved atoms and $\mathrm{L}_{2}$ ordered precipitates which equals 1.23 [4]. This superposition will yield $\Delta \tau_{p \& z, t o t}$, the total increase of CRSS due to precipitates/zones. Also here the simplifying assumption will cause some variation in the in the accuracy of the model. As a rough indication it is estimated that $q_{z o n e}$ varies by $10 \%$ either side of the average value and this 
leads to variation in the predicted yield strength of up to $\pm 13 \mathrm{MPa}$ for the monolithic 8090 alloy close the peak aged condition. The MMCs contain very little GPB zones and, as a result, variation of $q_{\text {zone }}$ will have very little influence (less than $7 \mathrm{MPa}$ variation in yield strength).

For solid solution strengthening several types of superposition combined with various expressions for solution hardening have been proposed (e.g. [14]). However, solution hardening in our alloys is limited as compared to other contributions to the CRSS, and for the superposition of solid solution strengthening a linear superposition, i.e. $q_{s s}=1$, is justified. This yields $\Delta \tau_{\text {sol,tot }}$, the total increase of CRSS due to dissolved atoms. In this superposition of solution strengthening we will also take account of the CRSS of pure Al which is estimated to be $4 \mathrm{MPa}$ (the yield strength of $99.99 \%$ pure $\mathrm{Al}$ is $10 \mathrm{MPa}[36])$.

Dissolved atoms represent much weaker obstacles as compared to precipitates. Hence for superposition of solid solution and precipitate strengthening, $q$ is expected to be close to unity. For a Ni-based superalloy, which, similar to Al-Li based alloys, contain L1 $1_{2}$ ordered precipitates, $q_{\text {ss\&ppt }}$ has been found to equal 1.23 [4]. Other researchers [18,26,37] have used this value in successful analyses of strengthening in binary Al-Li alloys and we will adopt this value of $q_{\text {ss\&ppt }}$ for the present Al-Li-Cu-Mg alloys. The superposition will yield $\Delta \tau_{p \& z \& s s}$, the total increase of CRSS due to precipitates, zones and dissolved atoms. If $q_{\text {zone }}$ varies by $10 \%$ either side of the average value and this leads to variations in the predicted yield strength of up to $\pm 13 \mathrm{MPa}$.

\subsection{Deformation of polycrystalline materials and texture.}

\subsubsection{Deformation of polycrystalline textured monolithic alloys.}

In monolithic polycrystalline materials each grain will in principle have a different orientation and plastic deformation of the alloy will occur through plastic deformation of the individual grains by slip on specific slip systems. In the absence of other strengthening mechanisms, the (macroscopic) yield strength of a polycrystalline metal has been related to the CRSS of the crystals via various models $[38,39,40,41]$. In these approaches the (macroscopic) yield strength can generally be related to the CRSS by an equation of the type:

$$
\sigma_{y}=M \Delta \tau_{\text {tot }}
$$

Where $M$ is a constant (sometimes referred to as the Taylor factor). The lower bound solution for $M$ is obtained from the Sachs model [38] in which plastic deformation in a single slip system is considered (i.e. slip is heterogeneous). This single slip can only be achieved by relaxing the constraint of similar deformation of the grains and thus individual grains are allowed to deform differently. In texture free FCC materials the Sachs model gives $M_{S}=2.24$. In the Taylor model [39] each grain is assumed to deform in the same manner and consequently slip is homogeneous, i.e. slip occurs in several slip systems (at least five independent ones). In texture free materials the Taylor model gives the upper bound solution for $M$ (for texture free FCC metals: $M_{T}=3.07$ ) $[42,43]$. Self-consistent models, like the one due to Hutchinson [40], indicate that on average about 
3.5 slip systems are active and yield intermediate values for M. For texture free FCC metals Hutchinson's model gives $M \cong 2.6$ [41].

Work on the yield strength anisotropy of solution treated and aged monolithic 8090 alloys [42] has indicated that for the underaged condition the Sachs model is most appropriate for modelling the strength whilst in the peak aged and overaged conditions the yield strength anisotropy is intermediate between the Taylor and Sachs model predictions. In correspondence with this it has been shown that in underaged $\mathrm{Al}-\mathrm{Li}-\mathrm{Cu}-\mathrm{Mg}$ alloys, grains deform in a heterogeneous manner via the formation of slip bands, whilst the $\mathrm{S}^{\prime}$ formed in later stages of the ageing acts to cause a more homogeneous deformation [44]. In the present work we will incorporate this change from heterogeneous to homogeneous slip in a simplified manner by assuming that the effective $M$ is an average of $M_{T}$ and $M_{S}$ weighted by the strengthening contributions due to $S^{\prime}$ and $\delta^{\prime}$ :

$$
M=\frac{M_{T} \Delta \tau_{S^{\prime}}+M_{S} \Delta \tau_{\delta^{\prime}}}{\Delta \tau_{S^{\prime}}+\Delta \tau_{\delta^{\prime}}}
$$

where $M_{T}$ is $M$ according to the Taylor model and $M_{S}$ is $M$ according to the Sachs model. Generally, rolled (or extruded) alloys will have a specific rolling texture, which will influence the strength of the alloys through variation of $M_{T}$ and $M_{S}$. The textures of various rolled and flat extruded monolithic 8090 alloys have been characterised in various investigations [42,45,46,47], and all show similar relative densities of the three dominant texture components copper, brass and S, with minor contributions from Goss and cube textures. Following the weighting methods for texture components outlined in Ref. [42] combined with data in Refs. [46,47] it is calculated that for hot rolled monolithic 8090 sheet $M_{T}=3.2$ and $M_{S}=2.55$. For the present rolled, solution treated and aged monolithic 8090 alloy this procedure yields $M$ values between 2.85 and 2.95 .

\subsubsection{Deformation of polycrystalline MMCs.}

It is important to note that whilst the models mentioned in the previous section can be valid for certain specific types of deformation of monolithic polycrystalline alloys, these models can not be assumed to be valid for MMCs. As a specific example it is pointed out that the assumption of similar deformation of the crystals as made in the Taylor model can not be valid in MMCs because local differences of the positions of the ceramic inclusions relative to the individual grains will cause deformation of each grain to be different. Hutchinson [40] extended his model to composites by considering a grain surrounded by material which has isotropic elastic properties corresponding to the average elastic properties of the composite. However, it was pointed out [40] that the validity of this model for real composites is not clear, given that the deformation in the soft metal is dominated by the local stress fields around the hard reinforcing particles.

To our knowledge no models for deformation of polycrystalline MMCs which takes account of both multi slip on crystallographic planes, as well as inhomogeneous stress related to the distribution of the reinforcing phase, exists. However, in a qualitative manner it can be argued that the $M$ value of the Sachs model is the most appropriate one for this case (see Section 4). As texture in rolled and in 
extruded 8090 MMCs is weak [45,47], and will have a negligible effect on the proof strength, $M_{M M C}$ should equal 2.24 .

\subsection{Grain and subgrain strengthening}

Grain and subgrain strengthening can be estimated using Hall-Petch type relations (see e.g. Refs. [7, 48]). The recrystallised grain size in MMCs can generally be estimated by assuming that each reinforcing particle acts as nucleus for one recrystallised grain. Following Ref. 7 the strengthening contribution of the grains in the MMCs is estimated at $25 \mathrm{MPa}$. The strengthening in the monolithic alloy is mainly due to subgrains, because recrystallised grains are relatively large. The strengthening contribution is estimated at $10 \mathrm{MPa}$.

\subsection{Strengthening by dislocations.}

In MMCs generally a high dislocation density, $\rho_{d}$, is present as a result of plastic deformation of the metal around misfitting ceramic inclusions. In heat treated MMCs misfit is due to the different coefficient of thermal expansion (CTE), $\alpha$, of metal and ceramic inclusion. This type of strengthening is generally estimated using (see also Refs. [7,49,50]):

$$
\Delta \sigma_{\Delta \alpha \Delta T}=\mu b \rho_{d}^{1 / 2}
$$

with

$$
\rho_{d}=\frac{B f_{r} \Delta \alpha \Delta T}{b d\left(1-f_{r}\right)}
$$

where $B$ is a constant which depends on the shape of the particle, $d$ is the smallest dimension of the particles, $\Delta \alpha$ is the difference in thermal expansion $\left(210^{-5} \mathrm{~K}^{-1}\right)$ and $\Delta T$ is the temperature drop during the quench from the temperature at which dislocation annealing is effectively stopped to the final temperature of the quench (often room temperature). For $B$ values in the range of 4 to 12 for elongated rectanguloid particles to 17 for spherical particles have been proposed by various authors $[7,8,9,51]$. The particles in the present MMCs are irregularly shaped and angular and hence resemble mostly the rectanguloid particles. For our estimate we will use $B \cong 10, \Delta T \approx 300^{\circ} \mathrm{C}$ and $d$ $\cong 2 \mu \mathrm{m}$ which yields: $\Delta \sigma_{\Delta \alpha \Delta T} \approx 35 \mathrm{MPa}$.

\subsection{Strengthening of MMCs due to load transfer}

\subsubsection{Load transfer - homogeneous matrix strength}

For the case of a matrix with homogeneous strength, the load transfer to reinforcing particles can be estimated either from shear lag (SL) type models [52,53,54] or from established Eshelby theory (see e.g. Ref. [10]). The former considers cylindrically shaped inclusions whilst the latter considers ellipsoid inclusions. For short fibres, older SL type models [54] predict load transfers which are much lower than the Eshelby model (see Ref. [55]), and until recently Eshelby models were 
preferred over SL type models. Recently, it was shown that the SL model can be modified to obtain a new SL type model (termed the SSSL model) which predicts stress transfers that are much more in line with Eshelby model predictions, whilst it also fits well to experimental data on the Young's modulus of composites [55]. Hence, in the present work, we will use the SSSL model presented in [55].

Due to high load transfer to the reinforcement resulting from plastic deformation, MMCs have a high work hardening rate, and consequently the $(0.2 \%)$ proof stress can be considerably higher than the yield strength. In order to account for this "plastic stress transfer", the corresponding strength increment, $\Delta \sigma_{p s t}$, is predicted by the Eshelby-type model presented in Ref. [10] is used. The latter work shows that $\Delta \sigma_{p s t}$ depends on $f_{r}, s_{r}$, elasticity constants and the plastic strain of the composite $\varepsilon_{e}^{p}$, and is estimated at about $20 \mathrm{MPa}$ for the present Al-17vol\%SiC MMCs. From Ref. [55] the expression for the proof stress is:

$$
\sigma_{0.2}^{c} \cong\left[f_{r}\left(\frac{E_{r}}{E_{m}^{\prime}}-\frac{E_{r}-E_{m}^{\prime}}{E_{m}^{\prime}} \frac{\tanh \left(\gamma s_{r}\right)}{\gamma s_{r}}\right) \sigma_{y}^{m}+\Delta \sigma_{p s t}\left(\varepsilon_{e}^{p}\right)\right]+\left(1-f_{r}\right) \sigma_{y}^{m}
$$

with

$$
E_{m}^{\prime}=\frac{E_{r}\left[1-\operatorname{sech}\left(\gamma s_{r}\right)\right]+E_{m}}{2-\operatorname{sech}\left(\gamma s_{r}\right)}
$$

and

$$
\gamma=\sqrt{\frac{2 E_{m}}{E_{r}\left(1+v_{m}\right) \ln \left(1 / f_{r}\right)}}
$$

where $E$ is Young's modulus, $v$ is Poisson's ratio, $f_{r}$ is the volume fraction of reinforcement, $s$ is the aspect ratio; subscript $\mathrm{m}$ stands for matrix and $\mathrm{r}$ for reinforcement. For the present composites $\left(f_{r}=0.17, s_{r} \cong 1.5\right)$, the SSSL model predicts an increase of $19 \%$ of the total yield strength.

\subsubsection{Load transfer - case of PFZs}

On ageing of $8090 \mathrm{MMCs}$, zones devoid of $\delta^{\prime}$ phase develop around the ceramic particles (see Fig. 1, and Ref. [23]). It should be noted that although these zones are devoid of $\delta^{\prime}$ precipitates, hardening of the zones can still occur as a result of S' precipitation. Hence, for $8090 \mathrm{MMCs}$, the term precipitate free zone (PFZ) refers to a zone which is devoid of $\delta^{\prime}$ phase whilst $\mathrm{S}^{\prime}$ formation is largely similar to that in other parts of the matrix. PFZs around a ceramic inclusion will have a reduced yield strength as compared to the matrix further away from the inclusion. On incremental straining (i.e. during tensile testing) of the composite this will cause premature yielding in the PFZ, which will reduce the transfer of load from the matrix to the ceramic inclusion. Hence, the development of PFZs will reduce the yield strength of a composite. In order to calculate this effect, we will adopt the simplified model for stress transfer in MMCs in the presence of a weak interface layer that was presented in Ref. [55]: 


$$
\sigma_{0.2}^{c} \cong\left[f_{r}\left(\frac{E_{r}}{E_{m}^{\prime}}-\frac{E_{r}-E_{m}^{\prime}}{E_{m}^{\prime}} \frac{\tanh \left(\gamma s_{r}\right)}{\gamma s_{r}}\right) \sigma_{y}^{m}+\Delta \sigma_{p s t}\right] \frac{\sigma_{y}^{P F Z}}{\sigma_{y}^{m}}+\left(1-f_{r}\right) \sigma_{y}^{m}
$$

The derivation of the above equation was based on the SSSL model, i.e. it is a SL type approach. As large strains will develop in the PFZ strain hardening of this layer has to be taken into account. This is achieved by using the following theoretical expression of strain hardening $[12,56,57]$ :

$$
\begin{aligned}
\sigma_{y}^{P F Z} & =\sigma_{y, 0}^{P F Z}+M\left(0.35 G_{m} \sqrt{\frac{b}{d_{g}}}+0.25 G_{m} \sqrt{\frac{b f_{n s}}{2 r_{n s}}}\right) \sqrt{\varepsilon_{e}} \\
& =\sigma_{y, 0}^{P F Z}+K \sqrt{\varepsilon_{e}}
\end{aligned}
$$

where $d_{g}$ is the grain size, $f_{n s}$ is the volume fraction of non-shearable particles, $K$ is the strain hardening factor and $\sigma_{y, 0}^{P F Z}$ is the yield strength of the PFZ at zero pre-strain.

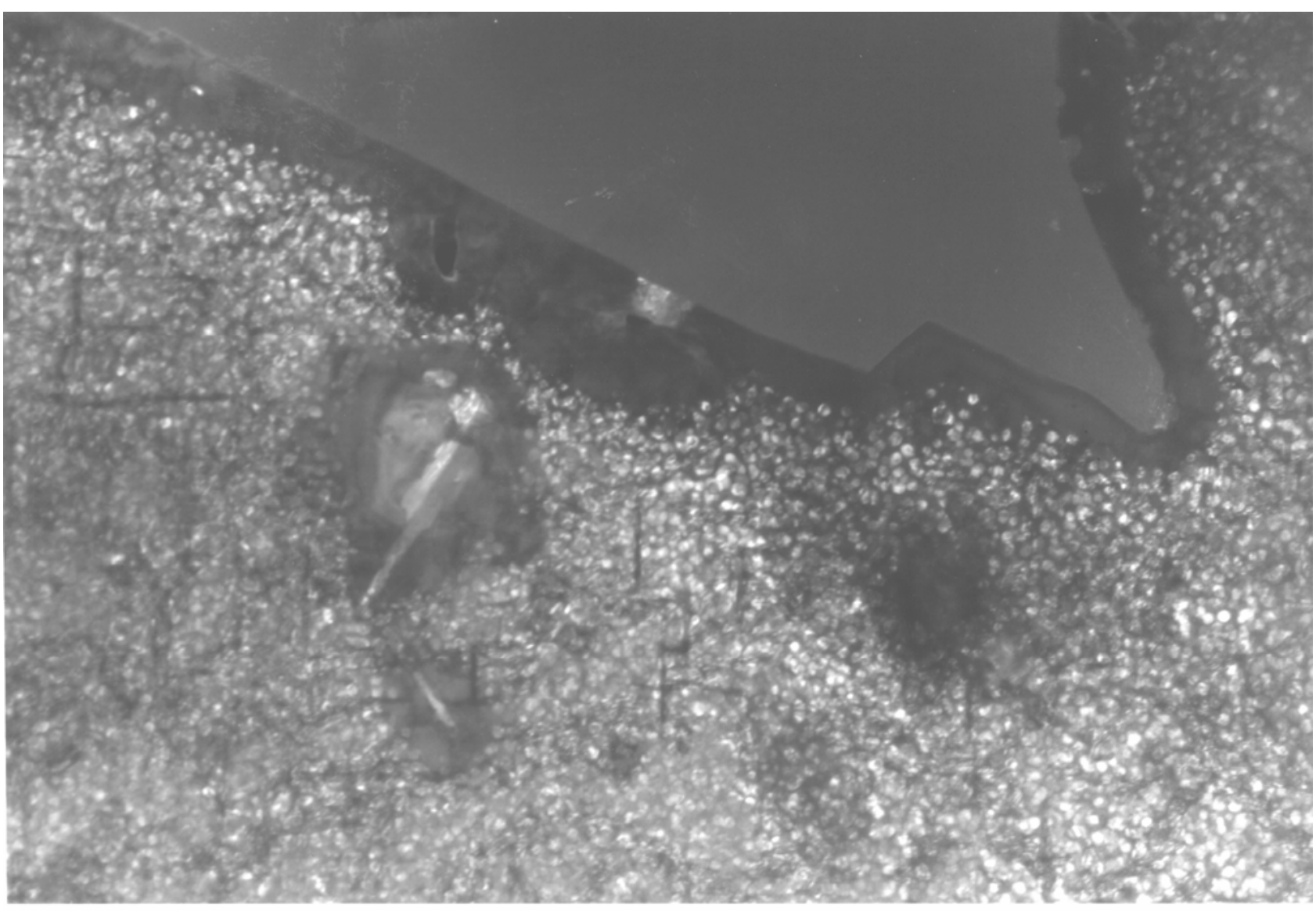

$50 \mu \mathrm{m}$

Fig. 1 TEM micrograph of the 8090 MMC showing a zone denuded of $\delta^{\prime}$ around a SiC particle. Dark field. 
In applying the model to the $8090 \mathrm{MMC}$ we will take $\sigma_{y, 0}^{P F Z}$ as the modelled yield strength of the grains in the Al-1.5 Li-Cu-Mg MMC. (Note that this means that $\sigma_{y, 0}^{P F Z}$ will vary during ageing as a result of GPB zone and $\mathrm{S}^{\prime}$ formation.) As the PFZ around the SiC particles is much smaller than the grains (i.e. there is no grain boundary in the PFZ), the grain boundaries will have no influence on strain hardening of the PFZ. Hence only the non-shearable $S^{\prime}$ and $\beta^{\prime}$ particles yield a significant contribution to $K$. From the average sizes and volume fractions of $S^{\prime}$ (see Ref. [19]) and $\beta^{\prime}\left(d_{\beta^{\prime}}=\right.$ $20 \mathrm{~nm}[23]$ and $d_{\beta^{\prime}} \approx 0.08 \mathrm{vol} \%$ ) it follows $K \approx 150 \mathrm{MPa}$.

The growth of PFZs in the $8090 \mathrm{MMC}$ has been analysed in detail in earlier work using TEM [23], and the growth of the PFZ is modelled using a square root law:

$$
d_{P F Z}=A_{2} t^{1 / 2}
$$

where $A_{2}$ is obtained by fitting data obtained for $d_{P F Z}[23]\left(A_{2}=0.014 \mu \mathrm{mh}^{-1 / 2}\right)$.

\section{$4 \quad$ Results and discussion}

\subsection{Validation of the model - Comparison of predicted and measured yield strengths.}

In the model outlined in section 3 two types of parameters appear: model parameters (elastic constants, $M, \gamma_{a p b}$ etc.) and microstructural parameters (sizes, volume fractions, PFZ size etc.). The model parameters are largely independent of the alloy and heat treatment and the microstructural parameters need to be measured for each alloy and heat treatment. In evaluating the models for strengthening all but one of the model parameters have been adopted from validated values published in the literature, the exception being $M_{M M C}$ which, in the absence of literature data, is estimated from the Sachs model (2.24). We will indicate this set of parameters as the 'preferred set' or set \#1. The microstructural parameters have been measured and analysed using TEM and quantitative DSC techniques [19,23]. It should be noted that at this stage of the evaluation no parameter has been fitted to the data for the present Al-Li-Cu-Mg based alloy and MMCs. A comparison of the predicted strengths with measured yield strengths is presented in Fig. 2 (for the individual alloys) and Fig. 3. In evaluating the quality of the fits in these figures it should be noted that uncertainties in the parameters (especially the q parameters, see section 3.3) result in uncertainties in model predictions, the magnitude of which is indicated in Fig. 2. Uncertainties in measured yield strengths are typically about $10 \mathrm{MPa}$. It is observed that in general, for all four alloys, a good correspondence between predicted and measured yield strengths is achieved and this indicates that that the presented model is essentially sound. The error bars indicate that differences between model predictions and measured data can be ascribed to the uncertainties in the model parameters, which mainly involves the values for q. The only sample for which a considerable and as yet unexplained difference between model prediction and measured proof stress if detected is the unaged $8090 \mathrm{MMC}$. (In the monolithic 8090 alloy aged for 7 days at $170^{\circ} \mathrm{C}$ both heterogeneously nucleated $\mathrm{S}^{\prime}$ and homogeneously nucleated $\mathrm{S}^{\prime}$ was observed. At this point it is assumed that for $\mathrm{S}^{\prime}$ 
strengthening in this alloy the size of the heterogeneously nucleated $S^{\prime}$ is the determining factor. This point is further discussed in section 4.2.)

In the 'preferred set' of parameters (set \#1) described above $M_{M M C}$ was taken as 2.24 , the value predicted by the Sachs model. This value can be rationalised by considering the shear stresses that develop in the matrix of an MMC during uniaxial straining. These shear stresses will be largest at cones in the direction of the tensile axis with a particle at the centre. The surfaces of these cones will at several points be parallel or nearly parallel with one of the 111 planes and at these points localised shear on the 111 plane is expected to occur. Hence, the shear stresses that occur during uniaxial straining will promote the heterogeneous slip on single slip planes characteristic of the Sachs model. Hence the present choice of $M_{M M C}$, based on the Sachs model, is thought to be correct.

In order to isolate and assess the effect of specific elements of the model, additional model calculations with parameters different from our set of preferred parameters were performed, and resulting accuracies, in terms of chi-squared values, are presented in Table 1. (For chi-squared calculation, the accuracy of yield strength determinations is taken as $10 \mathrm{MPa}$, the accuracy of the model calculations depends on the accuracies of the model parameters as estimated in Section 3.) The first group of results (sets \#2-5) in Table 1 investigates the consequences of the choice of a higher value for $M_{M M C}$. It can be seen that for $M_{M M C}=2.6$ (according to Hutchinson's model for a monolithic alloy) a reasonable performance of the model can only be maintained with unrealistically low values for the load transfer (sets \#2-4). Combined fitting of all the $M$ factors yield values of $M$ close to those obtained for the preferred set of parameters (set \#5). These results indicate that the present choice for $M_{M M C}$, as well as for $M_{T}$ and $M_{S}$ is essentially correct.

The part of the model dealing with PFZ development was further analysed by calculating model predictions assuming that PFZ development does not influence strengthening. This causes the predicted strengths for the aged $8090 \mathrm{MMC}$ to be about $100 \mathrm{MPa}$ higher than the measured ones, with an unacceptably high chi-squared (set \#6-8 in Table 1). Data in Table 1 shows that changing other model parameters can mitigate some of this severe reduction in accuracy, but this can only be achieved by choosing unrealistically low values for $M_{M M C}$ and $\sigma_{A P B}$. From this it is concluded that the part of the model dealing with PFZ development, which was newly developed for the present work, is an essential part of the strength modelling of MMCs.

The part of the model dealing with the superposition of the various contributions to the CRSS was further analysed by optimising the values of $q_{\text {zone }}$ and $q_{p p t}$ (set \#9 in Table 1). The resulting accuracy is only marginally improved by fitting these parameters and hence the slight deviation of the resulting values $\left(q_{\text {zone }}=1.21\right.$ and $\left.q_{p p t}=1.56\right)$ from the ones in the preferred set is not significant.

In a further assessment of elements of the model, the predictions of the present model for strengthening due to GPB zones are compared with available literature data on age hardening for several monolithic Al-Cu-Mg alloys [58,59,60]. The results of this comparison as presented in Table 2 show that the magnitude of the hardness increase during the first stage of hardening, which is due to GPB zone formation, can be predicted well (within about 15\%) by the current model. (Small deviations may be ascribed to either incomplete GPB zone formation or small contributions 
from minor amounts of S' precipitates.) Hence the present analysis of GPB strengthening which incorporates the estimated elasticity modulus of GPB zones $G_{G P B}$, appears to be reasonably accurate. It is further noted that during artificial ageing of Al-Cu-Mg alloys the first rapid stage of hardening is followed by an extended period during which no significant hardening occurs [58]. For an $\mathrm{Al}-1.1 \mathrm{at} \% \mathrm{Cu}-1.7 \mathrm{at} \% \mathrm{Mg}$ alloy aged at $150^{\circ} \mathrm{C}$ this hardness plateau stretches from 0.3 to $100 \mathrm{~h}$ [58]. As coarsening of GPB zones is inevitable, this indicates that the hardening contribution of GPB zones is independent of GPB zone size, but instead only depends on the volume fraction of the zones (see also Ref. [61]). This is consistent with the simplified strengthening model for GPB zones (modulus hardening) adopted in the present paper (Section 3.1.2). (It is further noted that in a monolithic Al-1.1at $\% \mathrm{Cu}-1.7 \mathrm{at} \% \mathrm{Mg}$ alloy aged for $100 \mathrm{~h}$ at $150^{\circ} \mathrm{C}$, i.e. just before the end of the hardness plateau, a dense distribution of very fine rod like structures is observed [58]. No conclusive identification of these structures was provided in Ref. [58]. The present interpretation of GPB zone hardening indicates that these structures must have a similar strengthening effect as the GPB zones. Hence they are either GPB zones or extremely fine, shearable S'.)

The above analyses show that the comprehensive model presented in section 3 is sound, and that it is able to accurately predict the strength of MMCs and monolithic alloys over a wide range of strengths and microstructural conditions. To our knowledge this is the first time a detailed and validated model for strengthening in heat treatable MMCs is presented.

Table 1: Accuracy of the model in terms of chi-squared for different combinations of parameters. The standard deviation in measured proof stresses was estimated as $10 \mathrm{MPa}$.

\begin{tabular}{|c|c|c|c|c|}
\hline $\begin{array}{c}\text { parameter } \\
\text { set }\end{array}$ & $\begin{array}{l}\text { based } \\
\text { on }\end{array}$ & modified parameters & fitted parameters & $\chi^{2}$ \\
\hline \#1 & & none & none & 1.30 \\
\hline \#2 & set \#1 & $M_{M M C}=2.6$ & none & 3.8 \\
\hline \#3 & set \#1 & $M_{M M C}=2.6$ & load transf. $9 \%, \Delta G=4.5 \mathrm{GN}$ & 2.1 \\
\hline \#4 & set \#1 & $M_{M M C}=2.6$, load transf. $15 \%$ & $\Delta \sigma_{\Delta \alpha \Delta T}=25 \mathrm{MPa}, \Delta G=5.0 \mathrm{GN}$ & 2.1 \\
\hline \#5 & set \#1 & none & $M_{M M C}=2.19, M_{T}=2.96, M_{S}=2.53$ & 1.2 \\
\hline \#6 & set \#1 & $\sigma_{y}^{P F Z}=\infty$ & none & 4.5 \\
\hline \#7 & set \#1 & $\sigma_{y}^{P F Z}=\infty, \sigma_{A P B}=0.05$ & $M_{M M C}=2.06$ & 2.2 \\
\hline \#8 & set \#1 & $\sigma_{y}^{P F Z}=\infty, \sigma_{A P B}=0.05, q_{p p t}=1$ & $M_{M M C}=1.82$ & 2.9 \\
\hline$\# 9$ & set \#1 & none & $q_{\text {zone }}=1.21$ and $q_{p p t}=1.56$ & 1.25 \\
\hline
\end{tabular}


Table 2: Strengthening and/or hardening increment during ageing for to several hours at 130 to $170^{\circ} \mathrm{C}$ for various $\mathrm{Al}-\mathrm{Cu}-\mathrm{Mg}$ based alloys. Model predictions for full precipitation of GPB zones are from the model described in section 3.

$*$ Vickers hardness is approximated using $\Delta \sigma_{\mathrm{y}}=2.1 \Delta \mathrm{HV}$.

\begin{tabular}{lccccccc} 
alloy (at\%) & $\mathrm{Cu}$ & $\mathrm{Mg}$ & $\Delta \mathrm{HV}$ & \multicolumn{2}{c}{$\Delta \sigma_{\mathrm{y}}(\mathrm{MPa})$} & Ref. \\
& $($ at\%) & $($ at\%) & meas & model* & meas & model & \\
& & & & & & & \\
Al-1.1Cu-1.7Mg & 1.1 & 1.7 & 32 & 39 & & & {$[58]$} \\
Al-1.4Cu-1.8Mg & 1.4 & 1.8 & 44 & 41 & & & {$[59]$} \\
2024 & 1.8 & 1.4 & 35 & 42 & & & {$[60]$} \\
Al-1.7Cu-1.9Mg-0.4Mn & 1.7 & 1.9 & & & 105 & 92 & {$[22]$}
\end{tabular}

It should be noted that the present work does not provide a direct evaluation of the accuracies of individual elements of the model, but rather shows that the elements can be integrated to form a detailed model applicable to a highly complex alloy. For example, whilst for order hardening by $\delta^{\prime}$ we are here following the treatment by Park and co-workers [27,28], additional work (data not reported) has shown that adopting alternative $B$ and $\gamma_{a p b}$ values used by Huang and Ardell $[15,16]$ leads to fits to data that are largely indistinguishable.

\subsection{S' strengthening of monolithic 8090 and Al-Cu-Mg type alloys}

Throughout the previous section it was assumed that for S' strengthening in all alloys the size of the heterogeneously nucleated $\mathrm{S}^{\prime}$ is the determining factor. However, after long term artificial ageing (several days at $170^{\circ} \mathrm{C}$ ) of one of the four alloys studied - the monolithic 8090 alloy - also fine homogeneously nucleated S' appears [19]. This possible complication only affects one of the data points in Fig. 2 (the monolithic 8090 alloy aged for $168 \mathrm{~h}$ at $170^{\circ} \mathrm{C}$ ). Moreover, Fig. 2 shows that the appearance of the homogeneously nucleated $\mathrm{S}^{\prime}$ is not related to an acceleration (or deceleration) of the strengthening of the monolithic 8090 alloy, and overall $\mathrm{S}^{\prime}$ strengthening can be described well by dispersion strengthening of $\mathrm{S}^{\prime}$ with sizes obtained from the heterogeneously nucleated S'. Thus it is concluded that the presence of homogeneously nucleated fine $S^{\prime}$ precipitates in one of the alloys does not influence the analyses in the previous section. 
$2 a$

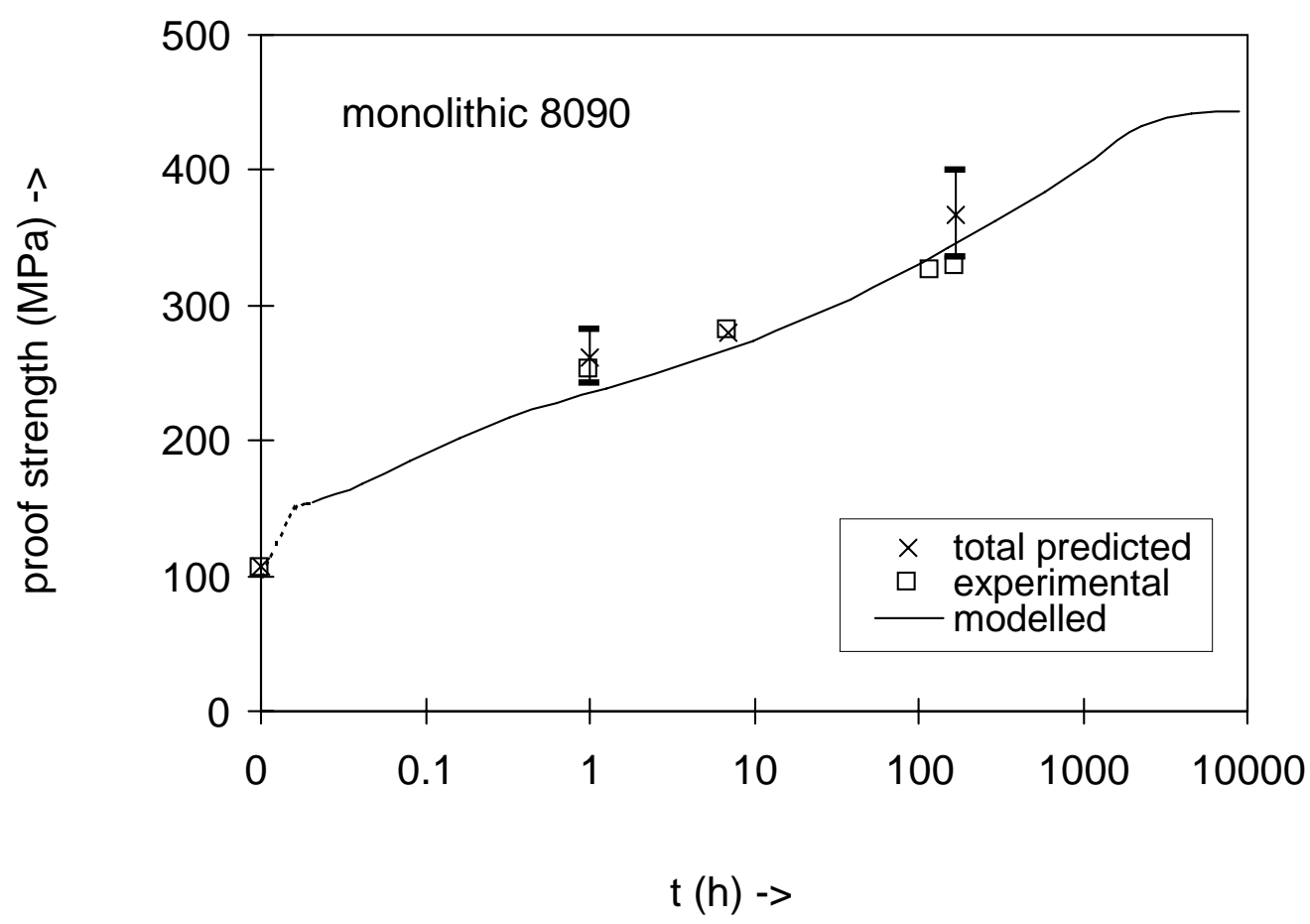

$2 b$

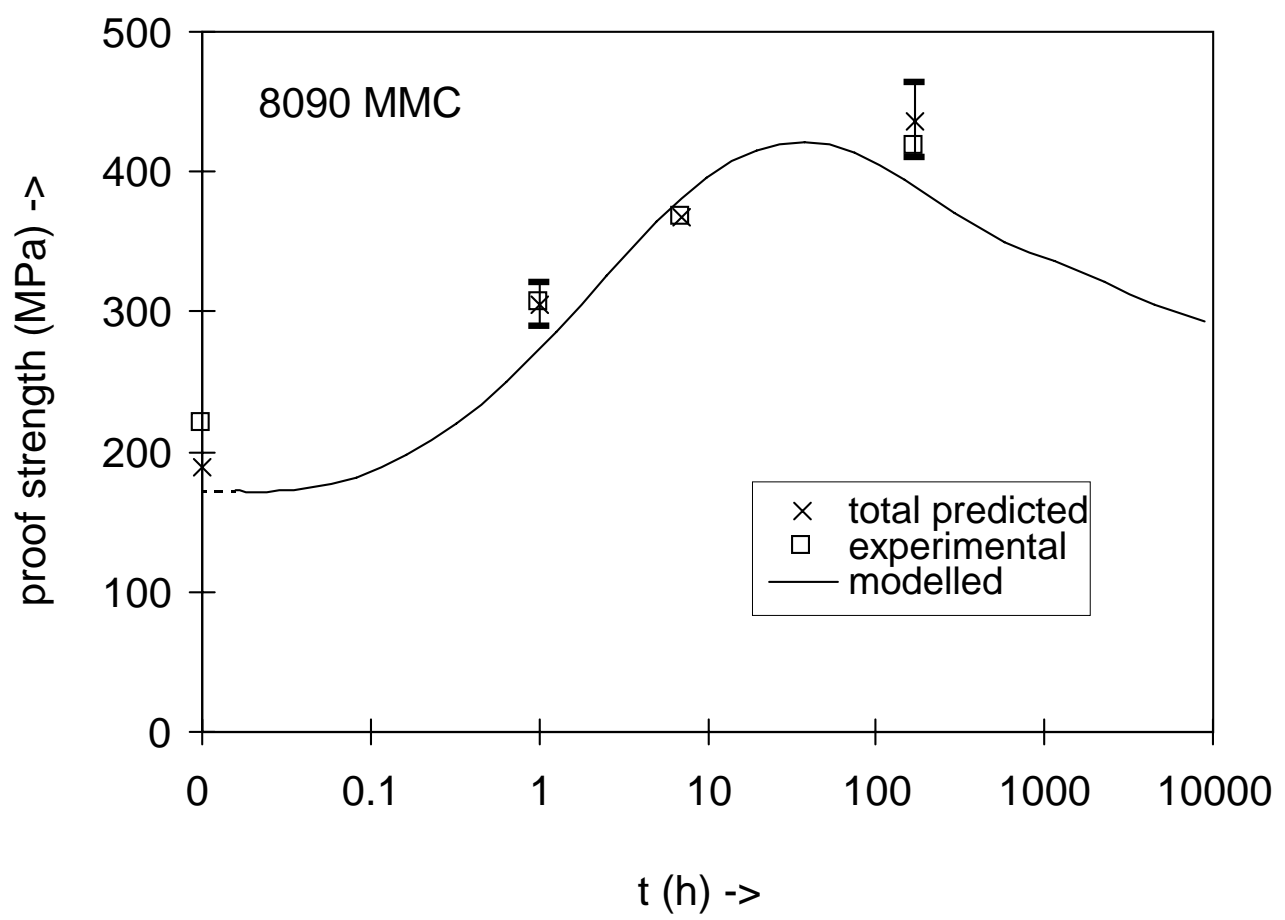


$2 c$

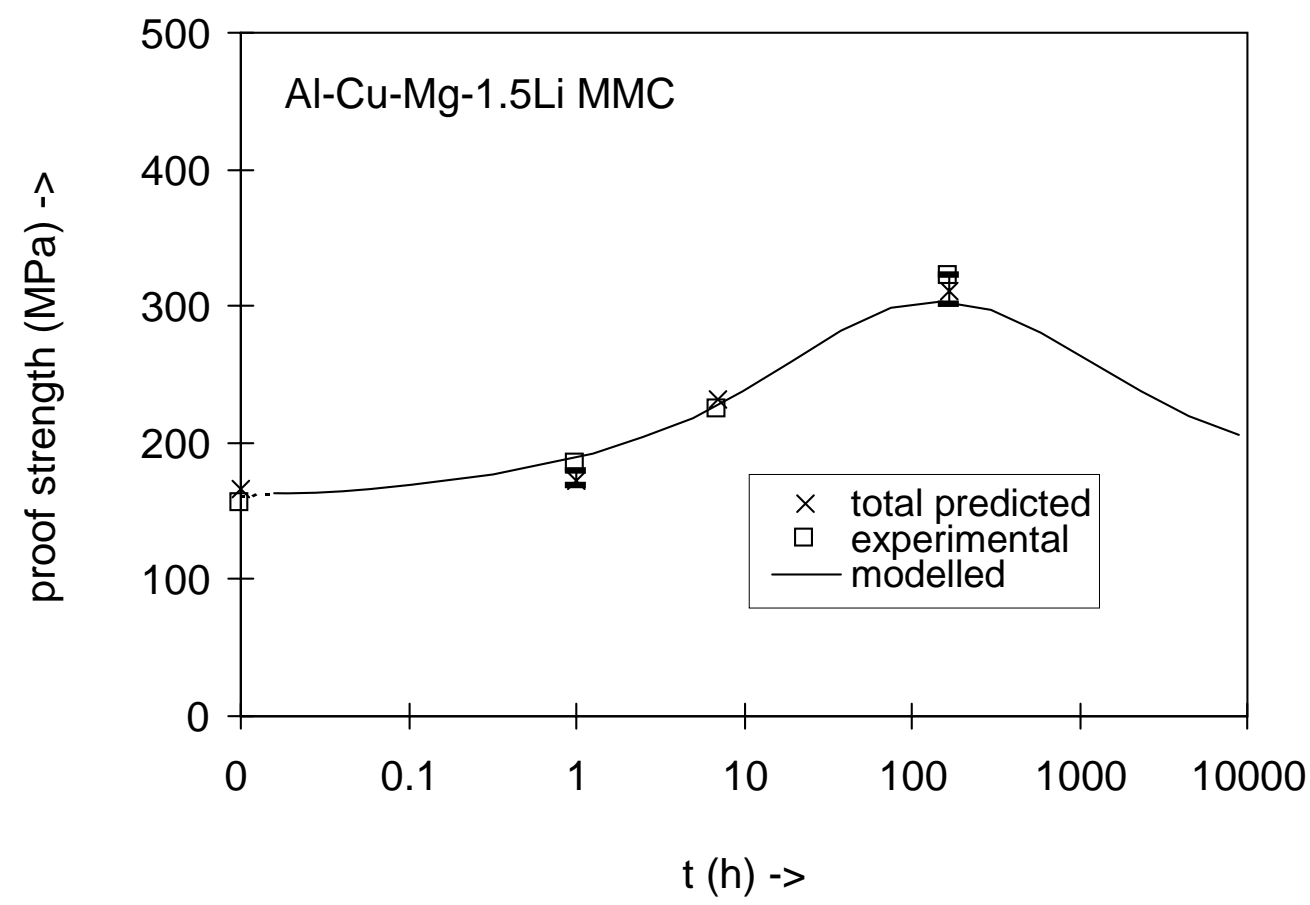

$2 d$

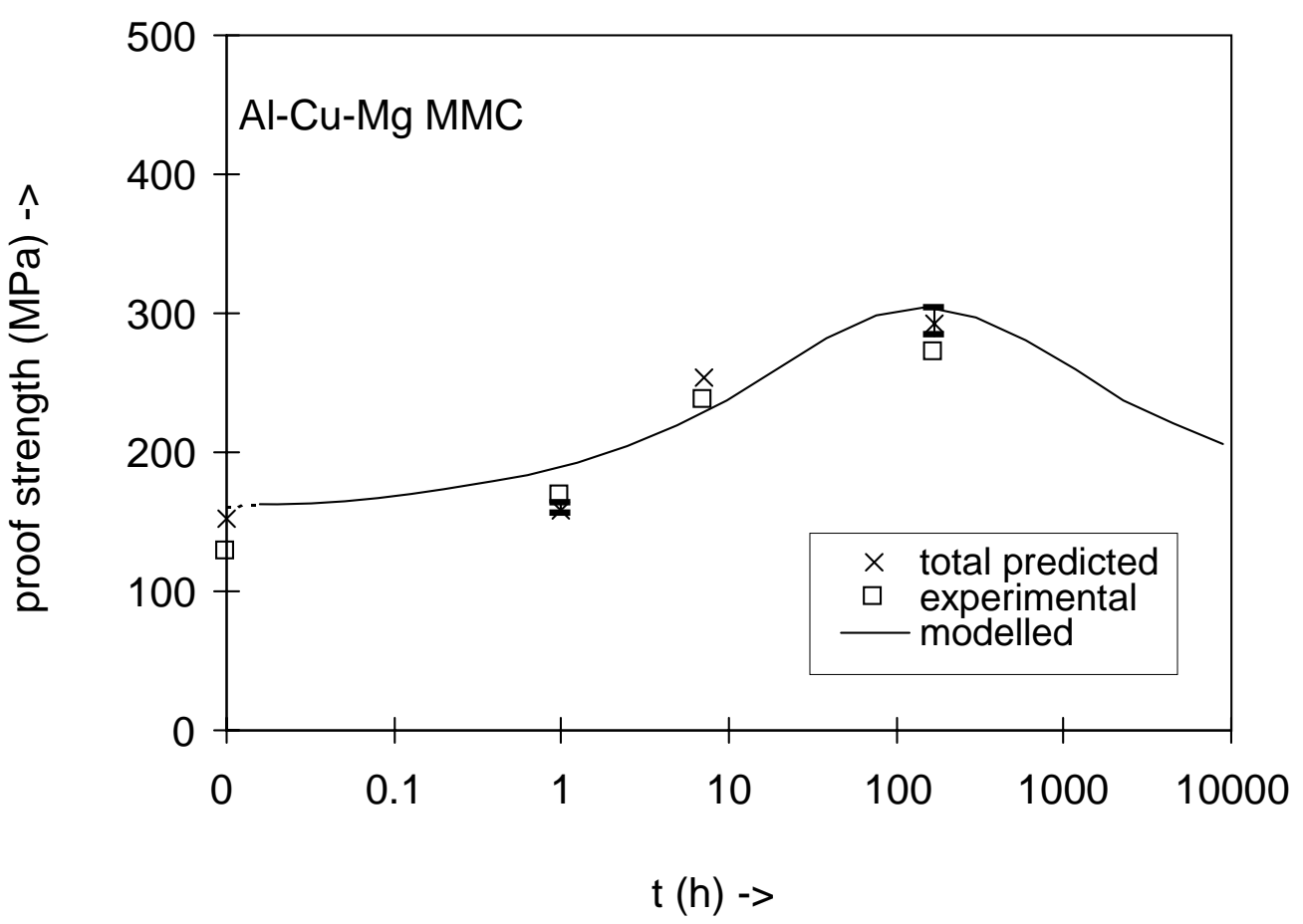

Fig. 2 Experimental $0.2 \%$ proof strengths of the 4 alloys compared with i) predicted proof strengths based on measured microstructural parameters and ii) predicted proof strengths based on microstructural parameters predicted by the model for kinetics of microstructure evolution, in Ref. [19]. 


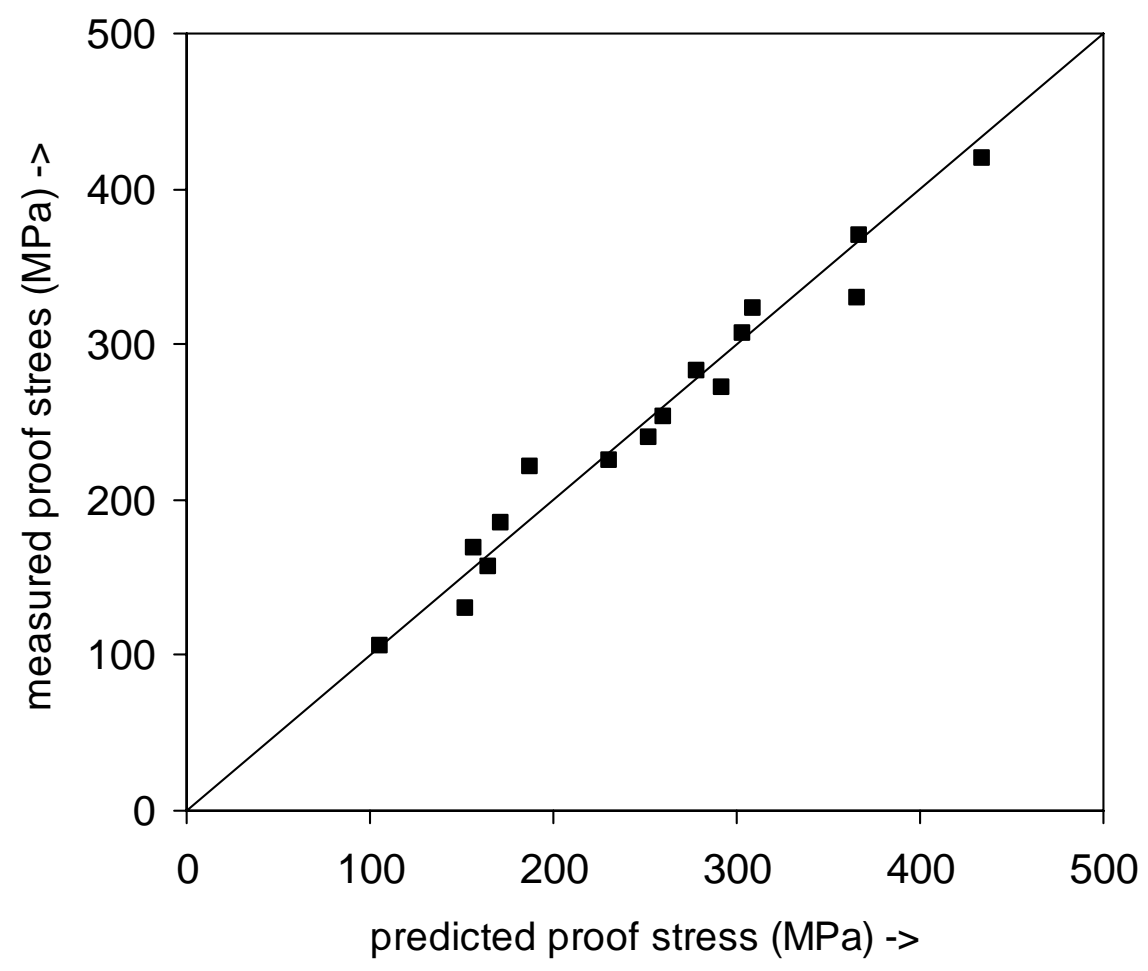

Fig. 3 Experimental $0.2 \%$ proof strengths of the 4 alloys compared the predicted proof strength based on measured microstructural parameters.

The absence of a marked acceleration of strengthening on the appearance of the dense distribution of homogeneously nucleated S' precipitates clearly indicates that these fine S' precipitates are shearable. Thus, for monolithic 8090 alloys and monolithic Al-Cu-Mg alloys, in which similar dual $S^{\prime}$ precipitation has been observed, S' strengthening will be due to two different types of strengthening: dispersion strengthening by non-shearable heterogeneously nucleated $\mathrm{S}^{\prime}$ and order strengthening by shearable homogeneously nucleated $\mathrm{S}^{\prime}$. The initial strengthening increase due to $\mathrm{S}^{\prime}$ will be due to formation of the non-shearable heterogeneously nucleated S'. In later stages this type of precipitation will slow down due to competition for $\mathrm{Cu}$ and $\mathrm{Mg}$ atoms by homogeneously nucleated S', and precipitation of homogeneously nucleated S' will become the main source of continued strengthening of the alloy. Also coarsening of the two types of $\mathrm{S}^{\prime}$ will influence strengthening: coarsening of heterogeneously nucleated non-shearable $\mathrm{S}^{\prime}$ will reduce strengthening whilst coarsening of homogeneously nucleated $S^{\prime}$ will enhance resistance against shearing and hence strengthen the alloy. It is further important to notice that the introduction of dislocations via stretching after solution treatment will enhance the formation of heterogeneously nucleated $\mathrm{S}^{\prime}$ at the expense of the homogeneously nucleated S'.

\subsection{Strengthening of 8090 type alloys and MMCs}

Having validated the model and its various elements in section 4.1 it is now possible to analyse the contributions of the different microstructural elements to the strengthening of 8090 type alloys and MMCs. In Fig. 4 the contributions of the various precipitates to the CRSS of the metallic matrix are 
presented together with the total CRSS of the metallic matrix using the superposition expressions defined earlier. This figure shows that for the $8090 \mathrm{MMC}$ the precipitate strengthening of the metallic matrix is dominated by $\mathrm{S}^{\prime}$ whilst precipitate strengthening in the monolithic 8090 alloy is initially mainly due to GPB zones, with $S^{\prime}$ and $\delta^{\prime}$ becoming important only in the later stages of ageing. Fig. 4 shows that for all samples, except for the overaged $8090 \mathrm{MMC}$, strengthening due to GPB zones is more important than strengthening due to $\delta^{\prime}$. This finding may appear surprising as in many publications on Al-Li-Cu-Mg type alloys (e.g. Refs. [45,23,62]) the strengthening due to GPB zones received little attention in comparison to $\delta^{\prime}$ strengthening. It is worth reiterating that the modelling of strengthening due to $\delta^{\prime}$ has been validated in various works $[3,4,15,16,26]$, whilst the strengthening due to GPB zones was validated in the previous section. Hence the present analysis of GPB and $\delta^{\prime}$ strengthening and their relative importance in 8090 alloys is sound.

Fig. 4 shows that the maximum precipitate strengthening in the MMC is reached within about 2 days of ageing at $170^{\circ} \mathrm{C}$ whilst the monolithic alloy strengthens at a much slower rate (the present model predicts peak strength to occur only after several years at $170^{\circ}$ ). This difference is due to enhanced rate of $\mathrm{S}^{\prime}$ formation in the MMC resulting from the enhanced dislocation density in the MMC. This point illustrates that the generation of dislocations by pre-stressing prior to ageing, which leads to standard commercial T8 type tempers, is an essential step in the processing of monolithic 8090 alloys, because:

i. It assures that significant precipitation strengthening can be achieved in a commercially acceptable ageing time.

ii. The enhanced formation of the non-shearable S' precipitates during ageing, which results from this pre-stressing, reduces the propensity of heterogeneous deformation by slip banding in aged alloys.

In Fig. 5 the predicted proof stress for the $8090 \mathrm{MMC}$ is compared with the proof stress of the Alrich phase with precipitates, the yield stress of the PFZ and the proof stress of the composite in the absence of a PFZ (i.e. a hypothetical MMC in which no PFZ forms). This figure shows that the time for peak ageing of the $8090 \mathrm{MMC}$ is mainly related to (over-)ageing due to the coarsening of precipitates. The development of the PFZs around the ceramic reinforcement strongly reduces the strength of the MMC, but, as this reduction mostly occurs before peak strength is reached, PFZ formation has little effect on the time for peak ageing of the $8090 \mathrm{MMC}$.

As a result of the formation of the PFZ, the strengthening effect of ceramic reinforcement becomes time-dependent, and can be divided into 4 regimes (Fig. 5):

- Initially (up to about $0.3 \mathrm{~h}$ ageing at $170^{\circ} \mathrm{C}$ ) the size of the PFZ and the strength difference with the rest of the matrix is too small for the PFZ to have any influence on strengthening.

- As, due to precipitation, the strength difference increases, whilst the PFZ grows relatively fast, the strengthening due to the reinforcement becomes less effective ( 0.3 to $5 \mathrm{~h}$ ageing).

- In the third regime (about 5 to $20 \mathrm{~h}$ ageing) the strengthening due to the reinforcement stabilises as a result of the combination of two effects: i) due to the $t^{1 / 2}$ growth law, the PFZ growth slows down, ii) the PFZ hardens somewhat as a result of $\mathrm{S}^{\prime}$ formation. For the $8090 \mathrm{MMC}$ the effective strengthening due to the 'reinforcement' becomes negligible in this regime. 
- Finally, in the overaged $8090 \mathrm{MMC}$ the strengthening due to the 'reinforcement' becomes more effective again. This is mainly due to the strength difference between matrix and PFZ reducing again as a result of matrix overageing.
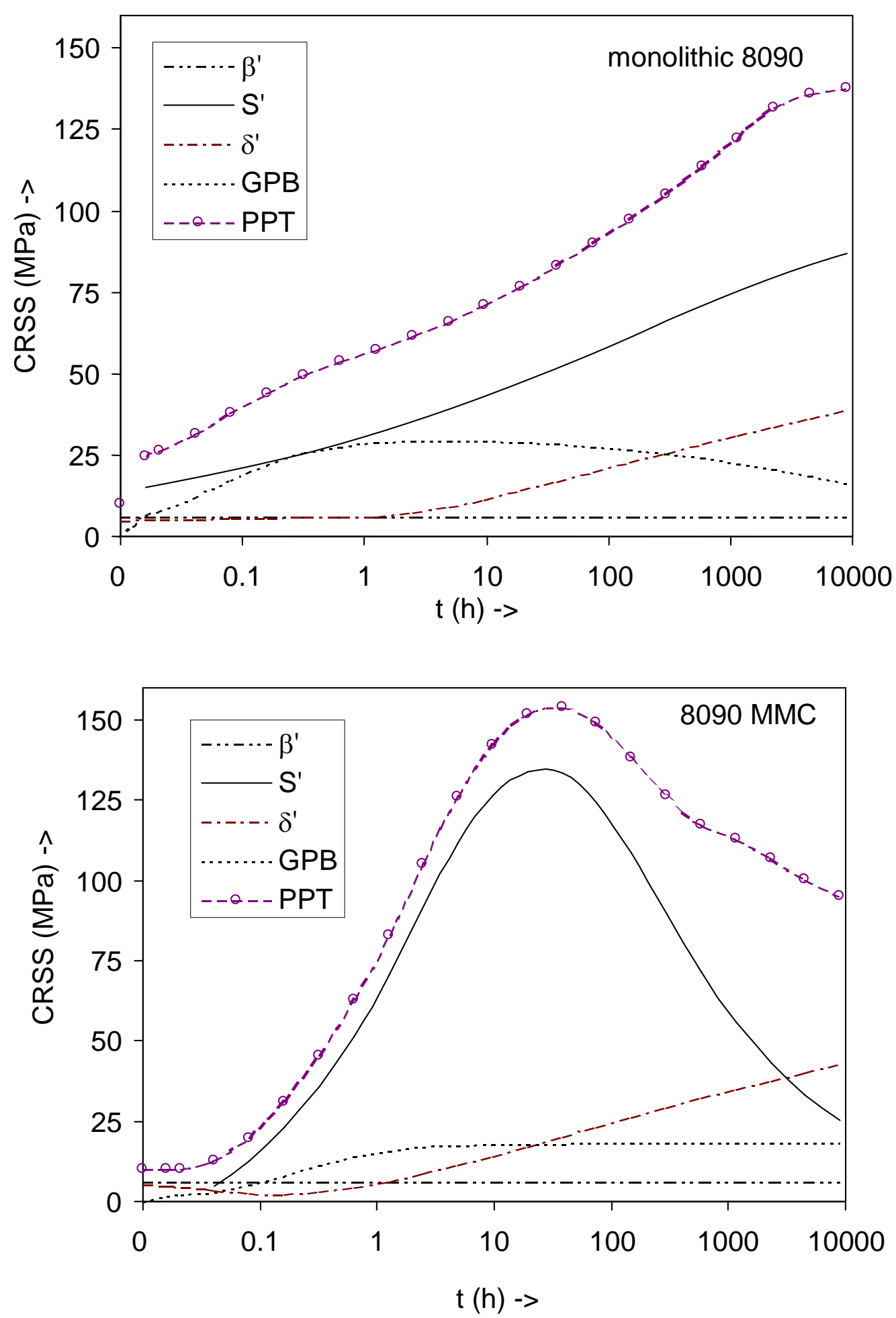

Fig. 4 Contributions of the various precipitates/zones to the CRSS of the grains in the monolithic 8090 and the $8090 \mathrm{MMC}$. PPT $=$ total CRSS of the grains. 


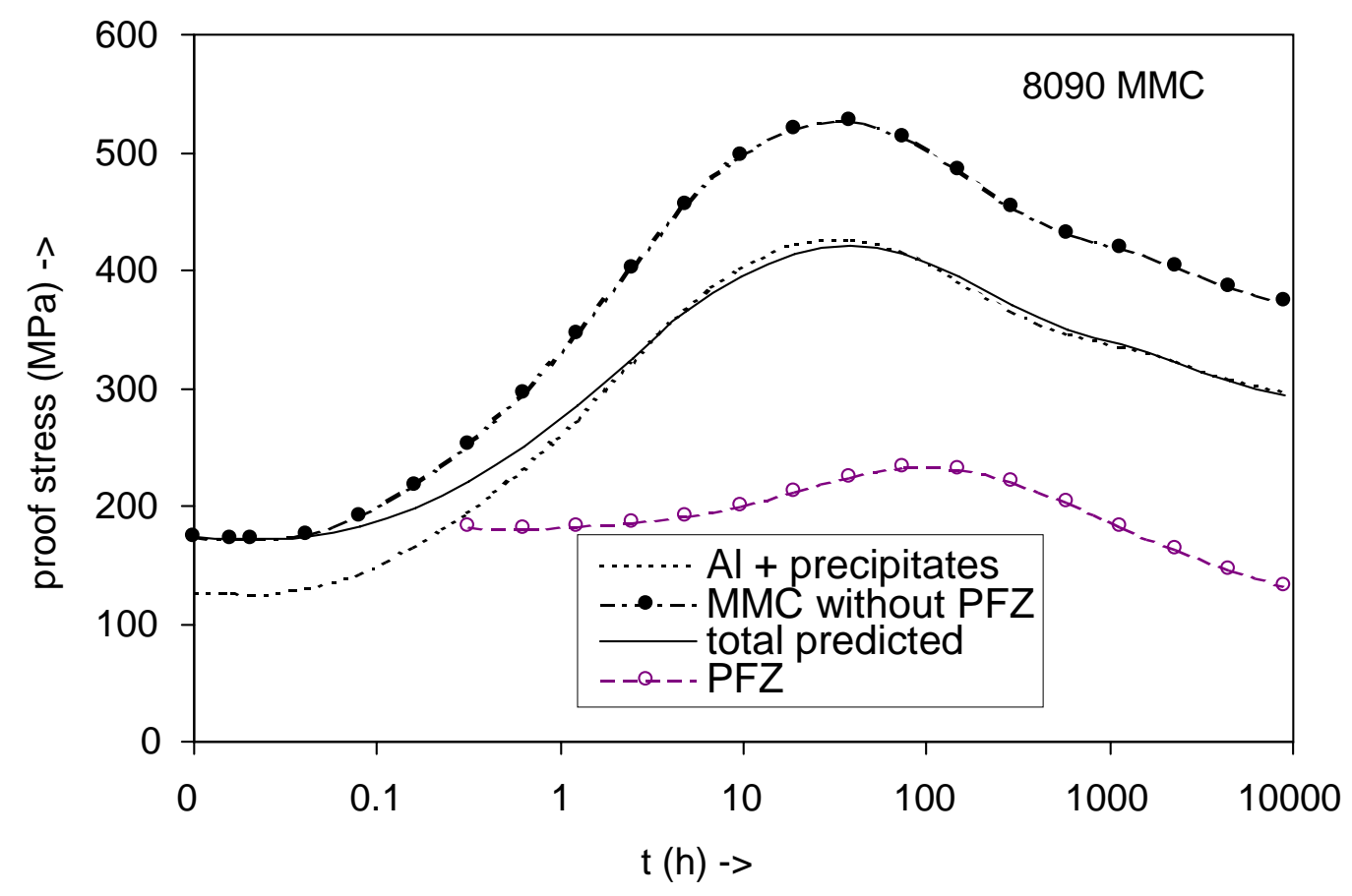

Fig. 5 The predicted proof stress for the $8090 \mathrm{MMC}$ compared with proof stress predictions for:

i) the Al-rich phase (including hardening precipitates),

ii) the composite in the absence of a PFZ,

iii) the PFZ (i.e. the Al-rich material adjacent to the SiC particle which is depleted in $\delta^{\prime}$ ).

The overall effect of PFZ development is that it mitigates the strengthening increase due to precipitation hardening of the matrix. Fig. 5 further illustrates that the development of the PFZ causes the peak strength of the MMC to be much lower than the strength that is reached in the hypothetical $8090 \mathrm{MMC}$ without PFZ. Thus the $8090 \mathrm{MMC}$ never reaches the full potential strength that might be expected on the basis of the precipitation hardened matrix combined with effective load transfer to the reinforcement. Fig. 5 indicates that in terms of the strength, the addition of ceramic particles to the 8090 alloy is only effective if the MMC is to be used in a very much underaged condition (less than $2 \mathrm{~h}$ ageing at $170^{\circ} \mathrm{C}$ ) or in an overaged condition.

\section{Summary}

A detailed model for the strengthening of monolithic alloys and composites has been presented. The model incorporates precipitation strengthening, solution strengthening by dissolved atoms, grain and subgrain strengthening, strengthening by dislocations and load transfer to ceramic inclusion, and it includes a new description for the effect of a precipitate free zone (PFZ) around the reinforcing phase. The model has been successfully applied to model the measured yield strengths of four Al-Li-Cu-Mg type alloys and composites. This work has shown: 
- The main factors involved in strengthening of monolithic 8090 type alloys are $\delta^{\prime}$ and GPB zone formation whilst $\mathrm{S}^{\prime}$ formation contributes only in the later stages of ageing. Heterogeneous deformation due to low amounts of S' phase causes a reduced yield strength as a result of a low $\mathrm{M}$ factor.

- The main factors involved in strengthening of 8090 type MMCs are $\delta^{\prime}$, GPB zone and S' formation and load transfer to ceramic inclusions.

- In all alloys aged at $170^{\circ} \mathrm{C}$ strengthening due to GPB zones is more important than strengthening due to $\delta^{\prime}\left(\mathrm{Al}_{3} \mathrm{Li}\right)$ phase.

- In the 8090 MMC formation of PFZs around ceramic reinforcements reduces the proof stress by up to $100 \mathrm{MPa}$. PFZs do not significantly alter the time needed to reach peak strength.

\section{List of symbols}

The following symbols have been used in the present paper and the companion paper [19]. In brackets values used in the preferred set of parameters are given.

$\Delta \mathrm{Q}_{\mathrm{GPB}, \mathrm{d}}$ heat evolution due to GPB-zone dissolution

$\Delta \mathrm{Q}_{\mathrm{S}^{\prime}, \mathrm{p}} \quad$ heat evolution due to $\mathrm{S}^{\prime}$ precipitation

$\Delta \mathrm{Q}_{\delta^{\prime}, \mathrm{d}} \quad$ heat evolution due to $\delta^{\prime}$ dissolution

$\Delta \mathrm{H}_{\mathrm{GPB}} \quad$ heat of formation of GPB zones

$\Delta \mathrm{H}_{\mathrm{S}^{\prime}} \quad$ heat of formation of $\mathrm{S}^{\prime}$ phase

$\Delta \mathrm{H}_{\delta^{\prime}} \quad$ heat of formation of $\delta^{\prime}$ phase

$\mathrm{n} \quad$ Avrami exponent (or reaction exponent)

$\eta_{i} \quad$ impingement factor

$\mathrm{f} \quad$ volume fraction of precipitates in matrix

c concentration of atoms in Al-rich phase

$\sigma_{0.2} \quad 0.2 \%$ proof stress

$\sigma_{\mathrm{y}} \quad$ yield stress

$\varepsilon \quad$ strain

$\mathrm{S}_{\mathrm{r}} \quad$ aspect ratio of reinforcing ceramic phase

$1_{\mathrm{r}} \quad$ length of reinforcing ceramic phase in the direction of the tensile stress

$f_{\mathrm{r}} \quad$ volume fraction of reinforcing ceramic phase

$\mathrm{d}_{\mathrm{g}} \quad$ average grain size

$\mathrm{d}_{\mathrm{sg}} \quad$ average subgrain size

$\mathrm{d}_{\mathrm{PFZ}} \quad$ width of PFZ

$\mathrm{M}_{\mathrm{T}} \quad$ Taylor factor

$\mathrm{M}_{\mathrm{S}} \quad$ Sachs factor

$\mathrm{M}_{\mathrm{MMC}} \quad$ Effective $\mathrm{M}$ factor for MMCs

b Burger's vector

$\tau \quad$ Critical resolved shear stress (CRSS)

$\Delta \tau_{\text {sol,size }}$ CRSS increment due to dissolved atoms resulting from the size effect

$\Delta \tau_{\text {sol,mod }}$ CRSS increment due to dissolved atoms resulting from the modulus effect 
$\Delta \tau_{\text {sol,SRO }}$ CRSS increment due to dissolved atoms resulting from SRO

$\Delta \tau_{\text {ord,ua }}$ CRSS increment due to order strengthening in the underaged condition

$\Delta \tau_{\text {ord,pa }} \quad$ CRSS increment due to order strengthening in the peak aged condition

$\Delta \tau_{\text {dis }} \quad$ CRSS increment due to dispersion strengthening

$\Delta \tau_{\text {mod }} \quad$ CRSS increment due to modulus strengthening

$\Gamma \quad$ line tension of dislocation

$\gamma_{\mathrm{APB}} \quad$ anti-phase boundary energy (of the $\delta^{\prime}$ phase)

G shear modulus

$\mathrm{G}_{\mathrm{GPB}} \quad$ shear modulus of GPB zones

$\mathrm{G}_{\mathrm{Cu}} \quad$ shear modulus of copper

$\mathrm{G}_{\mathrm{Mg}} \quad$ shear modulus of magnesium

$\left(0.118 \mathrm{~J} / \mathrm{m}^{2}[27,28]\right)$

$\mathrm{G}_{\mathrm{Al}} \quad$ shear modulus of aluminium

(48.3 GPa [63])

(17.3 GPa [63])

$\mathrm{E}_{\mathrm{m}} \quad$ modulus of elasticity of matrix

(26.2 GPa [63])

$\mathrm{E}_{\mathrm{r}} \quad$ modulus of elasticity of reinforcement

(74 GPa (Al))

$(450 \mathrm{GPa}(\mathrm{SiC}))$

q exponent for superposition of grain strengthening components

$\mathrm{q}_{\mathrm{ppt}} \quad \mathrm{q}$ for superposition of various precipitates

$\mathrm{q}_{\text {zone }} \quad \mathrm{q}$ for superposition of precipitates and zones

$\mathrm{q}_{\mathrm{ss}} \quad \mathrm{q}$ for superposition of various types of dissolved atoms

$\mathrm{q}_{\text {ss\&ppt }} \quad \mathrm{q}$ for superposition of precipitate/zone and dissolved atoms

$\Delta \alpha \quad$ difference in CTE between matrix and ceramic reinforcement

$\mathrm{K}$ strain hardening factor

\section{Acknowledgements}

The authors are grateful to EPSRC and DERA for funding parts of this research and to Dr. A. Shakesheff of DERA Farnborough for supplying the alloys. 


\section{References}

1 N.F. Mott and F.R.N. Nabarro, Proc. Phys. Soc., 1940, 52, 86.

2 E. Orowan, in Symposium on Internal Stresses in Metals and Alloys, Session III Discussion, Institute of Metals, London, U.K., 1948, p. 451.

3 A.J. Ardell, Metall. Trans. A., 1985, 16, 2131.

4 E. Nembach and G. Neite, Prog. Mater. Sci., 1985, 29, 177.

5 J.D. Eshelby, Proc. Roy. Soc. A., 1957, 241, 376.

6 J.D. Eshelby, Proc. Roy. Soc. A., 1959, 252, 561.

7 W.S. Miller and F.J. Humphries, in Fundamental Relationships Between Microstructure \& Mechanical Properties of MMCs, ed. P.K. Law and M.N. Gungor, TMA, Warrendale, Pa., USA, 1990, p. 157.

8 M. Taya, Mater. Trans. JIM, 1991, 32, 1.

9 D.C. Dunand and A. Mortensen, Acta Metall. Mater., 1991, 39, 127.

10 T.W. Clyne and P.J. Withers, in "An Introduction to Metal Matrix Composites", Cambridge University Press, Cambridge, U.K., 1993.

11 M.Z. Butt and P. Feltham, J. Mater. Sci., 1993, 28, 2557.

12 P. Gomiero, Y. Brechet, F. Louchet, A. Tourabi and B. Wack, Acta Metall. Mater., 1992, 40, 857.

13 U.F. Kocks, Metall. Trans. A. 1985, 16, 2109.

14 H.A. Roth, C.L. Davis and R.C. Thomson, Metall. Mater. Trans. A., 1997, 28, 1329

15 J.C. Huang and A.J. Ardell, Mater. Sci. Eng. A, 1988, 104, 149.

16 J.C. Huang and A.J. Ardell, Acta Metall., 1988, 36, 2995.

17 H.R. Shercliff and M.F. Ashby, Acta Metall. Mater., 1990, 38, 1789.

18 C. Schlieser and E. Nembach, Acta Metall. Mater., 1995, 43, 3983.

19 M.J. Starink, P. Wang, I. Sinclair and P.J. Gregson, Acta Mater., 1999, 47, 3841

20 H.M. Flower and P.J. Gregson, Acta Metall., 1985, 33, 527

21 M.J. Starink and P.J. Gregson, Scr. Metall. Mater., 1995, 33, 893.

22 A.J. Shakesheff, unpublished work, 1993, Defence Evaluation and Research Agency, Farnborough, U.K.

23 M.J. Starink and P.J. Gregson, Mater. Sci. Eng. A, 1996, 211, 54.

24 L.M. Brown and R.K. Ham, in "Strengthening Methods in Crystals", ed. A. Kelly and R.B. Nicholson, Elsevier, Amsterdam, The Netherlands, 1971, p. 9.

25 V. Gerold, H.J. Gudladt and J. Lendvai, Physica Status Solidi A, 1992, 131, 509

26 E. Nembach, Scr. Mater, 1997, 36, 1409.

27 S.M. Jeon and J.K. Park, Acta Mater., 1996, 44, 1449

28 B.C. Lee and J.K. Park, Acta Mater., 1998, 46, 4181

29 H. Tsukabino, R. Nozato, T. Sakurai, Y. Hasegawa and Y. Hayashi, Mater. Sci. Techn., 1994, 10, 222

30 L. Cartaud, J. Guillot and J. Grilhe, Proc. ICSMA IV, Nancy, vol. 1, p. 214 (1976).

31 E. Nembach, Phys. Stat. Sol. A, 1983, 78, 571

32 C.P. Blankenschip, PhD thesis, 1992, University of Virginia, USA.

33 R.D. Schüller, F.E. Wawner and A.K. Sachdev, J. Mater. Sci., 1994, 29, 239.

34 F. Livet and Y. Bréchet, J. Physique C3, 1987, 48, 357.

35 A.J.E. Foreman and M.J. Makin, Can. J. Phys., 1967, 45, 511. 
36 L.F. Modolfo, in Aluminium Alloys: Structure and Properties, Butterworths, London, U.K., 1976.

37 B. Noble, personal communication, 1998.

38 E. Sachs, Z. Ver. Deutsch. Ing., 1928, 72, 734.

39 G.I. Taylor, J. Inst. Metals, 1938, 62, 307.

40 J.W. Hutchinson, Proc. R.. Soc. London A, 1970, 319, 247

41 B. Clausen, T. Lorentzen and T. Leffers, Acta Mater., 1998, 46, 3087

42 G. Tempus, W. Calles and G. Scharf, Mater. Sci. Techn., 1991, 7, 937.

43 A.K. Vasudévan, M.A. Przystupa and W.G. Fricke, Mater. Sci. Eng. A, 1995, 196, 1.

44 D.C. Slavik, C.P. Blankenschip, E.A. Starke and R.P. Gangloff, Metall. Trans. A, 1993, 8, 1807

45 M.A. Przystupa, A.K. Vasudévan and A.D. Rollett, Mater. Sci. Eng. A, 1994, 186, 35

46 X.H. Zeng, M. Ahmad and O. Engler, Mater. Sci. Techn., 1994, 10, 581

47 A.W. Bowen, Mater. Sci. Techn., 1990, 6, 1058

48 C. Styles, S.M. Flitcroft, P.J. Gregson and P.D. Pitcher, Scr. Metall. Mater., 1991, 25, 1833.

49 M.J. Starink, V.M.F. Abeels and P. van Mourik, Mater. Sci. Eng. A, 1993, 163, 115.

50 C.Y. Barlow and Y.L. Liu, Acta Mater., 1998, 46, 5807.

51 R.J. Arsenault and N. Shi, Mater. Sci. Eng. A, 1986, 81, 175.

52 H.L. Cox, Br. J. Appl. Phys. 3, 1952, 72.

53 D. Hull and T.W. Clyne, in 'An introduction to Composite Materials', $2^{\text {nd }}$ ed., Cambridge University Press, Cambridge, U.K., 1996.

54 T.W. Clyne, Mater. Sci. Eng. A, 1989, 122, 183

55 M.J. Starink and S. Syngellakis, Mater. Sci. Eng. A., 1999, 170, 170

56 M.F. Ashby, Phil. Mag., 1966, 14, 1157.

57 M.F. Ashby, in "Strengthening Methods in Crystals", ed. A. Kelly and R.B. Nicholson, Elsevier, Amsterdam, The Netherlands, 1971, p. 137.

58 S.P. Ringer, K. Hono, I.J. Polmear, T. Sakurai, Appl. Surf. Sci., 1996, 94/95, 253.

59 N. Sen and D.R.F. West, J. Inst. Metals, 1969, 97, 87.

60 E. Hunt, P.D. Pitcher and P.J. Gregson, in 'Proc. International Conf. on Light Metals: Advanced Al and Mg Alloys', Amsterdam, The Netherlands, June 1990, ed. T. Khan and G. Effenberg, ASM, p. 687

61 J.M. Silcock, J. Inst. Metals, 1960-61, 89, 203

62 C.P. Blankenschip and E.A. Starke, Metall. Trans. A, 1993, 24, 833

63 Smithells Metals Reference Book, 7th ed., Butterworths-Heinemann Ltd, 1992 